\title{
Dietary patterns of the Andean population of Puna and Quebrada of Humahuaca, Jujuy, Argentina
}

\author{
D. Romaguera ${ }^{1}$, N. Samman ${ }^{2,3}$, A. Rossi ${ }^{3}$, C. $\operatorname{Miranda}^{2}$, A. Pons ${ }^{1}$ and J. A. Tur ${ }^{1 *}$ \\ ${ }^{1}$ Research Group on Community Nutrition and Oxidative Stress, Research Institute of Health Sciences, University of the Balearic \\ Islands, Guillem Colom Bldg, Campus, E-07122 Palma de Mallorca, Spain \\ ${ }^{2}$ Research Centre of Food Technology, Faculty of Engineering, National University of Jujuy, 4600 San Salvador de Jujuy, \\ Argentina \\ ${ }^{3}$ Department of Nutritional Biochemistry, INSIBIO, National University of Tucumán, 4000 San Miguel de Tucumán, Argentina
}

(Received 15 December 2006 - Revised 6 June 2007 - Accepted 19 June 2007)

The aim of the present study was to describe dietary patterns in a representative sample from Puna and Quebrada of Humahuaca, Jujuy, Argentina. A cross-sectional nutritional survey was carried out in a representative sample ( $n$ 1236) of individuals from these regions. For the present study, only children aged 2-9 years ( $n$ 360), adolescents aged $10-18$ years $(n 223)$ and adults aged 18 years or over $(n$ 465) were considered. Breast-fed children, pregnant women and lactating women were excluded. Dietary data collection methods comprised one $24 \mathrm{~h}$ recall and a semi-quantitative FFQ. We used principal component (PC) analyses to identify prevailing dietary patterns. Multiple linear regression analyses were performed to assess the determinants of the identified dietary patterns. Two dominant PC were identified: PC1 reflected a 'Western-like' diet with an emphasis on not-autochthon foods. This pattern tended to be present in urban areas of the Quebrada region and was associated with a younger age, a higher level of development, and a worse diet quality. PC2 reflected an 'Andean-like' diet including a variety of autochthon crops. This was preferred by individuals living in rural areas from Puna with a high level of development during the post-harvest season, and was associated with a greater diet quality. These results suggest that the nutrition transition phenomenon is a reality in certain sectors of this population and might be one of the leading causes of the observed double burden of malnutrition.

\section{Nutrient intake: Dietary patterns: Andean population: Argentina}

Since ancient times food availability and dietary patterns of populations living in the Andes have been determined by the environmental and seasonal conditions of this region. However, there is evidence that ancient pre-Columbian Andean populations developed advanced production and subsistence systems in order to cope with the adverse environmental conditions: agriculture and livestock systems were based on an appropriate use of the environment, the continuous improvement of food plants and domesticated animals and the interchange of products from various ecological areas. All these involved the optimisation of their diets and possibly led to the adequate physical and psychological development of ancient Andean populations ${ }^{1-3}$. However, this ancestral knowledge to deal with adverse environmental and seasonal conditions of the region seems to be disappearing. The marginalisation of typical Andean staple foods because of the low social prestige and the deterioration of natural resources (mainly soil and water) are leading to a very nutritionally poor Andean $\operatorname{diet}^{3-8}$. Moreover, due to historical, cultural and political reasons the quality of life of these populations is well below its true potential. Widespread poverty, a very slow rate of development, an increasing high population growth rate, unequal distribution of wealth and natural resources degradation leads to food insecurity and malnutrition ${ }^{7,9,10}$.

Globalisation and urbanisation may also affect food supply and influence dietary patterns and lifestyle behaviours, as in many other Latin-American countries. A considerable body of literature has reported that traditional population groups throughout the world are replacing their traditional food patterns rich in complex carbohydrates, micronutrients, fibre and phytochemicals with diets high in refined sugars, animal products and highly processed foods. This nutrition transition phenomenon produces the dual problem of widespread under-nutrition persisting in the same population in which more Western-type diets are leading to obesity and chronic diseases ${ }^{11-13}$.

The aim of the present study was to describe current dietary patterns of the Andean population of Puna and Quebrada of Humahuaca, Jujuy, Argentina. We have used the a posteriori approach (principal component (PC) analyses) in order to reduce the dimensionality of the data, to identify groups with different dietary habits, and to evaluate the dependence of these food patterns on socio-demographic and other dietary conditions. 


\section{Material and methods}

\section{Population and sample}

The present study is a population-based cross-sectional nutritional survey carried out in the Andean regions of Puna and Quebrada of Humahuaca, in the province of Jujuy, NorthWestern Argentina at the intersection with Chile and Bolivia. The inhabitants of these regions are descendants of indigenous ethnic groups. With the exception of a humid subtropical area at about $1500 \mathrm{~m}$ above sea level in the valley of the Quebrada of Humahuaca, the rest of the region is an arid high plain located at about $3500 \mathrm{~m}$ above sea level. The vegetation is sparse and the climate is dry and harsh with high daily thermal oscillations. In the humid region of the Quebrada of Humahuaca, agriculture is an important economical activity together with livestock, tourism and few extractive industries. In the Puna region, livestock of sheep, goats and llamas is the main economic activity, whereas agriculture is limited to family subsistence crops ${ }^{14}$.

The target population consisted of all inhabitants living in the Puna and Quebrada regions (82922 individuals according to the last national census, 2000) (National Institute of Statistics and Censuses, 2006; http://www.indec.gov.ar/). The theoretical sample size was set at 500 families comprising 1500 individuals (a rough number of three individuals were planned to be interviewed in each family) in order to provide a specific relative precision of $5 \%$ (type I error $=0 \cdot 05$; type II error $=0 \cdot 10$ ), a design effect of 2 to account for the clustersampling procedure, and taking into account an anticipated $70 \%$ participation rate. The selection of the sample was done by stratified random cluster-sampling procedures. The final sample size was 1236 individuals aged $0-86$ years (359 families; participation rate of $72 \%$ ).

For the present study only children (aged 2-9 years) that were not breastfed, adolescents (aged 10-18 years) and adults (aged $>18$ years), excluding pregnant and lactating women, were considered (sub-sample size 1048).

\section{Questionnaires}

A questionnaire divided into two parts was designed for the present study. The first questionnaire was intended to gather general information of the whole family and included questions related to the household status, socio-economic level of the family, educational level of the head of the household, food supply and security and access to healthcare systems. This first questionnaire was answered by an adult member of each household. The second part was specific for each member of the household participating in the study. This included questions related to individual educational level, health status, dietary habits, physical activity pattern, a nutritional survey and an anthropometric assessment. These questionnaires were tested for reliability and suitability in two populations of Puna and Quebrada (ninety-five individuals) before the beginning of the study.

\section{Dietary questionnaire}

Dietary data collection methods comprised a $24 \mathrm{~h}$ recall and a semi-quantitative FFQ. The fieldwork was carried out from May to December 2005 in two waves: the first one was from early May to mid July (post-harvest season) and the second wave was from mid October to late November (preharvest season). The questionnaires were administered homogeneously from Monday to Sunday. Family members present in the house at the moment of the interview answered the dietary questionnaire.

In order to estimate usual portion and serving sizes, representative samples of local foods were weighed and volume of household bowls and cups normally used in the community were measured at the beginning of the study. In order to accurately perform the $24 \mathrm{~h}$ recall, we asked the individual responsible for cooking (in the house or in school canteens) about the ingredients, amounts and cooking technique of meals consumed the previous day. Normally the cook knew the number of ladles, dishes or glasses that would result from the recipe and each individual reported how many of household servings were consumed. We calculated the total volume in the pot and the proportion served to each individual. Homogeneity of contents was assumed unless otherwise indicated. When individuals had meals outside the house, we asked about type and amount of food consumed.

Dietary pattern was assessed by means of a semi-quantitative FFQ. This included forty-six foods grouped in thirteen food groups. The serving size of each food item was determined according to the observed amount consumed usually in this population as described above.

To convert food consumption into nutrient (energy and macronutrient) intakes, Argentinean and Latin-American food composition tables were used ${ }^{15}$. For foods not included in these tables (i.e. chewing-gums, cola, instant juices, breakfast cereals, concentrated soup and canned tuna), Spanish food composition tables were used ${ }^{16,17}$.

\section{Anthropometric measurements}

Height and weight measurements were taken of children, adolescents and adults according to Frisancho's recommendations ${ }^{18}$.

Height was determined using a mobile anthropometer (Kawe 44 444; Kirchner \& Wilhelm GmbH, Asperg, Germany) to the nearest $\mathrm{mm}$, with the subject's head in the Frankfurt plane. Body weight was determined to the nearest $100 \mathrm{~g}$ using a digital scale (Tefal charm, sc 2504; Rumilly, France). The subjects were weighed after taking off shoes and heavy clothes (the rest of the weight of clothes was accounted for by subtracting $200 \mathrm{~g}$ in children and $400 \mathrm{~g}$ in adults from the measured weight).

In children and adolescents, their weight status (according to their BMI $\left(\mathrm{kg} / \mathrm{m}^{2}\right)$ ) and their height status (height-for-age) were compared with WHO/National Center for Health Statistics/Centers for Disease Control reference standards by means of centiles (BMI) and Z-scores (height-for-age) ${ }^{19}$. Nutritional status of adults was determined using the WHO classification according to their BMI (underweight was defined as BMI $<18.5 \mathrm{~kg} / \mathrm{m}^{2}$, normal weight as BMI $18.5-$ $24.9 \mathrm{~kg} / \mathrm{m}^{2}$, overweight as BMI $25-29.9 \mathrm{~kg} / \mathrm{m}^{2}$ and obesity as $\left.\mathrm{BMI}>30 \mathrm{~kg} / \mathrm{m}^{2}\right)^{20}$.

\section{Socio-economic status}

The socio-economic condition of the family was assessed according to their household status. The household status 
was derived according to seven variables about the sanitation and hygienic conditions of the household: type of floor (soil, others); number of rooms $(1,2-3,>3$ ); electricity (no, solar energy, yes); toilets (no, latrine, yes); waste pipe (no, septic chamber, yes); separated kitchen (no, yes); drinkable water (no, yes). A household status score (HSS) was constructed in order to facilitate the analysis. Each category of these seven variables received a score to construct the composite HSS ( $0,0.5$ and 1 for variables with three categories; 0 and 1 for variables with two categories; total score range $0-7$ ). In order to facilitate the analyses, the continuous variable HSS was divided into three categories according to the distribution of the HSS values in the sample (HSS $<4$ was codified as low HSS, a score between 4 and 5.5 as medium HSS, and above 5 as high HSS).

\section{Statistics}

Analyses were performed with SPSS version 12.0 (SPSS Inc., Chicago, IL, USA). Descriptive analysis relied on cross-tabulations, showing percentages within groups as well as group medians, mean values and standard deviations.

PC analyses were applied to the total sample. The original forty-six dietary variables (food item consumption derived from the FFQ) were considered as residuals from linear regressions of each of these on total energy intake over all age groups and sexes to control for the role of energy intake on the reported individual food intake ${ }^{21}$. In this way, the correlations between foods would be based on dietary choices and/or food availability rather than reflecting between-individual variation in overall quantities of intake. Dietary patterns were identified by means of PC extracted from PC analysis ${ }^{22}$. PC were extracted using the correlation matrix in order to adjust for unequal variances of the original variables. To identify the number of $\mathrm{PC}$ to be retained, we used the criterion of eigenvalues exceeding 1. Food groups (residuals) with absolute scoring coefficients $>0.2$ were considered to be important contributors to a component (food pattern). A positive scoring coefficient indicates that the original dietary variable is positively associated with the respective PC, whereas a negative scoring coefficient implies an inverse association. Dietary patterns were expressed as the scores of each PC retained; these were calculated by summing the standardised values of the food groups (residuals) weighted by their scoring coefficients. Thus, each individual received a score for each identified pattern. We labelled patterns on the basis of those food groups, the consumption of which is reflected by high, positive scores in the respective component.

Multiple regression models were fitted for each of the dietary pattern scores on socio-demographic characteristics: age (in 10-year increments, continuous); sex (males and females, by category); region (Puna and Quebrada, by category); area (urban including suburban and rural, by category); season (post-harvest and pre-harvest, by category); HSS (in 1-point increments, continuous).

\section{Results}

Table 1 shows the socio-demographic characteristics of the sample. It was composed of 588 women and 460 males. The mean age of the whole group was 23.0 (SD 18.7) years and the median age was 17.0 years. Around half of the sample was interviewed in the pre-harvest season and the other half during the post-harvest season. The distribution of the sample in the two regions (Puna and Quebrada of Humahuaca) and within each area (urban, suburban and rural) was proportional to the population density. The mean HSS was 4.7 (SD 1.5) and the median score was 5.0 (data not shown).

Table 2 shows the anthropometric characteristics of the sample. Average BMI values of children and adolescents lay slightly above percentile 50 of the reference standards; however, the distribution of $Z$-score values for their height-forage was slightly skewed to the left, indicating that on average the height of children and adolescents was somewhat lower than expected for children and adolescents of their age and sex. The mean BMI of adults was slightly greater than the acceptable maximum value $\left(25 \mathrm{~kg} / \mathrm{m}^{2}\right)$.

Table 3 shows the energy, macronutrient, fibre and cholesterol content of the diet by sex and age group. Overall, the median percentage of energy provided by total carbohydrates, fats and proteins was $64.6,22.9$ and $11.8 \%$, respectively. Most proteins came from vegetable sources $(57.3 \%$ of proteins). There was an important contribution of simple sugars to the total energy intake $(20.0 \%)$. The median sample fibre intake was about $13 \mathrm{~g} / \mathrm{d}$. The percentage of energy from saturated fat was less than $10 \%$ and cholesterol consumption was lower than $24 \mathrm{mg} / 1000 \mathrm{~kJ}$ in all sex and age groups.

Table 4 shows median food group consumption in this community. Roughly, the daily food pattern consisted of three or four servings of cereals (including bread), about one serving of potatoes, two servings of fruit and vegetables, about one serving of meat $(50 \mathrm{~g})$ and one or two servings of fat and/or

Table 1. Socio-demographic characteristics of the sample

\begin{tabular}{ll}
\hline Characteristic & $\%$ \\
\hline Sex & \\
Male & $43 \cdot 9$ \\
Female & $56 \cdot 1$ \\
Age & \\
$\quad$ Children (2-9 years) & $34 \cdot 4$ \\
Adolescents (10-18 years) & $21 \cdot 2$ \\
Adults (>18 years) & $44 \cdot 4$ \\
Region & \\
Quebrada & 47.5 \\
Puna & 52.5 \\
Area & \\
Urban & $53 \cdot 2$ \\
Suburban & 18.0 \\
Rural & 28.9 \\
Season & \\
Post-harvest & $47 \cdot 0$ \\
Pre-harvest & 53.0 \\
HSS & \\
Low (< 4) & 39.3 \\
Medium (4-5.5) & 29.1 \\
High ( $>5.5)$ & 31.6 \\
\hline
\end{tabular}

HSS, household status score.

* The household status was assessed according to seven variables about the sanitation and hygienic conditions of the household (type of floor; number of rooms; electricity; toilets; waste pipe; separated kitchen; drinkable water). Each category of these seven variables received a score to construct the composite HSS, with a score range of $0-7$. The continuous variable of the HSS was divided into three categories according to the distribution of the HSS in the sample. 
Table 2. Anthropometric characteristics of the sample*

(Mean values and standard deviations)

\begin{tabular}{|c|c|c|c|c|c|c|c|c|c|c|c|c|}
\hline \multirow{3}{*}{$\begin{array}{l}\text { Age group... } \\
\text { Characteristic }\end{array}$} & \multicolumn{4}{|c|}{$2-9$ years } & \multicolumn{4}{|c|}{$10-18$ years } & \multicolumn{4}{|c|}{$>18$ years } \\
\hline & \multicolumn{2}{|c|}{ Male } & \multicolumn{2}{|c|}{ Female } & \multicolumn{2}{|c|}{ Male } & \multicolumn{2}{|c|}{ Female } & \multicolumn{2}{|c|}{ Male } & \multicolumn{2}{|c|}{ Female } \\
\hline & Mean & SD & Mean & SD & Mean & SD & Mean & SD & Mean & SD & Mean & SD \\
\hline Age (years) & $5 \cdot 1$ & $2 \cdot 2$ & $5 \cdot 2$ & $2 \cdot 2$ & $12 \cdot 4$ & $2 \cdot 1$ & $12 \cdot 9$ & $2 \cdot 3$ & $39 \cdot 0$ & $15 \cdot 5$ & $40 \cdot 8$ & $15 \cdot 7$ \\
\hline Weight (kg) & $19 \cdot 1$ & 5.7 & $18 \cdot 6$ & $5 \cdot 8$ & $40 \cdot 7$ & $10 \cdot 7$ & $42 \cdot 3$ & $11 \cdot 3$ & $66 \cdot 9$ & $12 \cdot 5$ & $59 \cdot 8$ & $12 \cdot 4$ \\
\hline Height (cm) & $107 \cdot 2$ & $15 \cdot 2$ & $107 \cdot 4$ & $16 \cdot 0$ & $147 \cdot 4$ & $12 \cdot 4$ & $145 \cdot 8$ & 12.5 & $162 \cdot 3$ & $13 \cdot 8$ & $151 \cdot 8$ & 5.4 \\
\hline BMI $\left(\mathrm{kg} / \mathrm{m}^{2}\right)$ & $16 \cdot 1$ & 1.9 & $16 \cdot 3$ & $2 \cdot 1$ & $18 \cdot 6$ & $3 \cdot 1$ & $20 \cdot 0$ & $6 \cdot 1$ & $25 \cdot 2$ & $4 \cdot 0$ & $26 \cdot 3$ & $6 \cdot 0$ \\
\hline BMI centile & $57 \cdot 7$ & $29 \cdot 8$ & $56 \cdot 9$ & $28 \cdot 8$ & $49 \cdot 1$ & $28 \cdot 3$ & $54 \cdot 4$ & $28 \cdot 3$ & - & - & - & - \\
\hline HA Z-score & -0.4 & 1.3 & -0.5 & 1.5 & -0.8 & $1 \cdot 1$ & -0.8 & 1.0 & - & - & - & - \\
\hline
\end{tabular}

HA, height-for-age.

${ }^{*} \mathrm{BMI}$ centiles and HA Z-scores were calculated to compare the observed values to the reference standards ${ }^{19}$

oils. Eggs and legumes were consumed about twice per week each and fish was never consumed by most of the population. Herbal teas with sugar were consumed on a daily basis (two or three servings of each per d). One serving of sugary drinks was consumed nearly every day. Dairy products were consumed daily by children in the sample (one serving per d). Children consumed sweet or dairy desserts twice per week.

PC analyses identified fourteen dietary patterns on the basis of the eigenvalue $>1$ criterion. These PC explained approximately $61 \%$ of the total variance in daily food intake. However, due to the lack of any meaningful interpretability of some of these components, only the first two PC were used to adequately describe some of the prevailing dietary patterns in this population. Table 5 shows the main constituents of each of the two dominant dietary components, adjusted for total energy intake. Large coefficients indicate strong associations between the food groups and the corresponding pattern and therefore reflect a high consumption. Negative scores imply the opposite pattern of consumption. PC1 reflects a 'not-autochthon, Western-like' diet with positive scoring coefficients for foods such as beef, common bread, chicken and sugary drinks and negative scoring coefficients for lamb, bollo and tortilla, Creole potatoes, mote, llama and other indigenous foods. PC1 reflects an 'autochthon, Andean-like' diet with a high consumption of vegetable products such as vegetables, cereals, tubers, legumes and fruit together with some animal products such as eggs or cheese. The consumption of herbal teas and sugary products is also representative of this dietary pattern.

Table 6 shows multiple regression-derived, mutually adjusted partial regression coefficients and their corresponding standard errors and $P$ values of the two identified PC regressed on socio-demographic variables. The 'not-autochthon, Western-like' PC1 was positively associated with HSS and negatively associated with age. It was also negatively associated with the Puna region and rural areas. No significant association was found between this pattern and seasonality. The 'autochthon, Andean-like' PC2 was positively associated with HSS, the Puna region, rural areas and post-harvest season.

Table 7 shows the Spearman correlation coefficients and $P$ values of each PC on several dietary variables. PC1 was positively correlated with protein and animal protein, simple sugar and cholesterol intake, whereas it was negatively correlated with complex carbohydrates and fibre intake. On the other hand, individuals scoring high on PC2 were likely to show greater intakes of vegetable proteins, total carbohydrates and fibre while the intake of animal proteins and lipids tended to be low.

\section{Discussion}

The present study has described the dietary intake of a representative sample of individuals from the Andean regions of Puna and Quebrada of Humahuaca (Jujuy, Argentina). Furthermore, we have explored energy-adjusted dietary patterns and we have investigated their relationship to socio-demographic characteristics.

The distribution of the sample in terms of age group, sex, area and region was proportional to the population density. The socio-economic status of most of the population in the region, according to the observed household status, was very low. Other variables such the occupational level of the head of the household (low in $70 \%$ of the population) and the reported income (less than US\$1 per person per $d$ in $80 \%$ of individuals) confirm these observations (data not shown). However, in previous studies we have shown that, in the present population, the status of the household is the variable that better reflected the socio-economic condition of the family and level of development, given the overall low levels of education, occupation and income ${ }^{23}$. For this reason we use a composite measure of the household status, HSS, as an indicator of socio-economic conditions and level of development.

Values of weight-for-height in children, adolescents and adults were within the normal range or even greater than recommended. In a previous study we reported that $22 \%$ of children and $14.4 \%$ of adolescents showed either overweight or obesity (BMI percentile $\geq 85$ ) and $50.6 \%$ of adults had a BMI $>25 \mathrm{~kg} / \mathrm{m}^{2}$ (Romaguera et al. ${ }^{23}$ ). On the other hand, wasting was not a major nutritional problem in the present community (5 and $6 \%$ of children and adolescents, respectively, showed a BMI percentile $<5 ; 1 \%$ of the adult sample had a BMI $<18.5 \mathrm{~kg} / \mathrm{m}^{2}$ ). The low values of height in children, adolescents and adults $(10.7 \%$ of children and $12.4 \%$ of adolescents showed $Z$-score values of height-forage $<-2 \mathrm{SD}$, indicative of stunting) reflect that growth retardation, chronic malnutrition and deprivation at the household level are important nutritional problems. Therefore the double 
burden of malnutrition (coexistence of overweight and stunting at the population level) is a reality in this community. Several biological and ecological factors may be responsible of this phenomenon. Among them, it is worth mentioning the changes in dietary and physical activity patterns associated with the nutrition transition. The quality of new foods introduced in the diet, at most times rich in energy but poor in nutrients, may adversely affect the growth of the child but provide sufficient energy for the adult to gain excess weight ${ }^{24}$. Also nutritional interventions aiming to address the problem of malnutrition of one member of the household by increasing food availability may put the rest of the family at risk of excess weight ${ }^{25,26}$. However, other biological factors unique in developing countries might exacerbate the effects of these ecological factors ${ }^{12}$. The possible explanation of why so many individuals become obese under such circumstances might have its origin in evolutionary roots. The 'thrifty genotype' hypothesis proposes that individuals adapted to chronic famine might increase their susceptibility to hoard energy as fat in times of abundance and develop obesity ${ }^{27-29}$. Other theories link low birth weight or childhood stunting with a higher predisposition to becoming obese ${ }^{13,27,28,30-32}$.

Median values of dietary intake and food patterns observed in this population confirm that the diet of the present sample resembles traditional dietary patterns from Andean regions with some typical peculiarities of the nutrition transition. For instance, the high consumption of grains and tubers and the low intake of animal products (meat and dairy products), total fat, saturated fat and cholesterol are more typical from Andean diets than from diets of countries in the Southern Cone (Argentina, Chile, Paraguay and Uruguay) ${ }^{11}$. However, some characteristics such as the high intake of refined grains and sugars resulting in a low intake of fibre are typical aspects of the nutrition transition. Also, the percentage of energy from carbohydrates $(65 \%)$ is lower than what was normally found in rural Andean communities (80\%) and energy from fat is higher $(23 v .15 \%)^{6}$.

Food patterns were further analysed using an a posteriori approach (PC analyses) in order to identify different dietary patterns and their relationship with socio-demographic and other dietary variables. Two major PC were identified, which reflected important contrasts between food patterns. PC1 showed a 'not-autochthon, Western-like' dietary pattern, with an emphasis on newly introduced foods rather on indigenous foods. This dietary pattern was preferred by younger, urban subjects, with higher levels of development, living in the Quebrada region. Furthermore, this dietary pattern seemed to be unrelated to the time of the year. Nowadays the Quebrada region is expanding its tourism-based economy and, therefore, dietary habits of inhabitants might have been influenced by globalisation of food patterns. Globalisation, urbanisation and economic development are the leading causes of the nutrition transition phenomenon. These, together with the greater preference of this PC among the youth and the lack of effect of seasonality, may imply that this dietary pattern reflects the nutrition transition phenomenon in this community. Furthermore, this dietary pattern is directly and significantly correlated with animal proteins, cholesterol and simple sugar intake and inversely correlated with complex carbohydrates and fibre intake. These are typical dietary aspects of Western food patterns ${ }^{12}$. 
Table 4. Sample food pattern

\begin{tabular}{|c|c|c|c|}
\hline Food group & Type of foods & Serving size $(g)^{*}$ & Median consumption $†$ \\
\hline \multirow[t]{2}{*}{ Cereals and grains } & Bread, tortilla and bollo, biscuits & 50 & \multirow[t]{2}{*}{$3.4 \mathrm{~s} / \mathrm{d}$} \\
\hline & Pasta, polenta, rice, mote, quinoa & 60 & \\
\hline Potatoes and tubers & Creole potatoes, common potatoes, batata & 150 & $1.1 \mathrm{~s} / \mathrm{d}$ \\
\hline Pulses & Lentils, chickpeas, beans, peas & 60 & $1.3 \mathrm{~s} / \mathrm{w}$ \\
\hline Meat and meat products & $\begin{array}{l}\text { Chicken, beef, pork, lamb, llama, entrails, } \\
\text { processed cold meat }\end{array}$ & 50 & $1 \cdot 2 \mathrm{~s} / \mathrm{d}$ \\
\hline Eggs & Hens' eggs & 60 & $1.5 \mathrm{~s} / \mathrm{w}$ \\
\hline Fish & Canned and fresh fish & 60 & $0.0 \mathrm{~s} / \mathrm{d}$ \\
\hline \multirow[t]{2}{*}{ Milk and dairy products } & Cows' milk, goats' milk, yoghurt & 200 & \multirow[t]{2}{*}{$4.4 \mathrm{~s} / \mathrm{w}(7-3 \mathrm{~s} / \mathrm{w} \ddagger)$} \\
\hline & Cheese & 50 & \\
\hline Fruits and vegetables & Fresh fruits, fresh and cooked vegetables & 150 & $2.0 \mathrm{~s} / \mathrm{d}$ \\
\hline Added oil & Mixed vegetable oil & 10 & $1.0 \mathrm{~s} / \mathrm{d}$ \\
\hline Animal fat used for cooking & Animal fat, butter & 10 & $2.2 \mathrm{~s} / \mathrm{w}$ \\
\hline Sugary drinks & Soft drinks, powdered instant juice & 150 & $3.4 \mathrm{~s} / \mathrm{w}$ \\
\hline Herbal teas & Tea, mate, herbs & 200 & $2.0 \mathrm{~s} / \mathrm{d}$ \\
\hline Added sugar and sweets & Table sugar, jam, honey, dulce de leche & 10 & $2.0 \mathrm{~s} / \mathrm{d}$ \\
\hline Sweet and milky desserts§ & Api, anchi, arroz con leche & 100 & $1.5 \mathrm{~s} / \mathrm{w}\left(2-1 \mathrm{~s} / \mathrm{w}^{\| 1}\right)$ \\
\hline
\end{tabular}

s/d, Servings per d; s/w, servings per week.

* Serving sizes were estimated according to the observed common amount of food consumed by the present population.

† Sample median consumption of food groups in servings is expressed on a daily or weekly basis according to the food group.

‡Range of consumption observed in the sample: from about $7 \mathrm{~s} / \mathrm{w}$ in children to about $3 \mathrm{~s} / \mathrm{w}$ in adults; about $4 \mathrm{~s} / \mathrm{w}$ were consumed by adolescents.

$\S$ Typical sweet and milky desserts were prepared with maize flour and/or milk and/or rice and/or fruit juice plus sugar and other ingredients.

॥ Range of consumption observed in the sample: from about $2 \mathrm{~s} / \mathrm{w}$ observed in children and female adolescents to about $1 \mathrm{~s} / \mathrm{w}$ observed in adults and male adolescents.

The second PC identified reflected an 'autochthon, Andeanlike' dietary pattern. This food pattern was based on a variety of foods, with an emphasis on indigenous crops plus some sources of proteins. This dietary pattern was preferred by individuals of all ages, with higher levels of development living in rural areas from Puna (the most isolated location of the studied regions). This PC reflected dietary choices of individuals during the post-harvest season. Previous research in rural Andean areas indicated that food availability was deeply influenced by seasonality and it was greater during the harvest and post-harvest season and lower during the pre-harvest season ${ }^{33}$. Oppositely to $\mathrm{PC} 1$, this dietary pattern was positively correlated with vegetable protein, complex carbohydrate and fibre intake and negatively correlated with animal protein and lipid intake. This PC seems to reflect a varied and equilibrated traditional dietary pattern present in this community; however, it is likely to be limited to individuals with high socio-economic status during the post-harvest season.

Some methodological limitations of the present study should be highlighted: the use of only one $24 \mathrm{~h}$ recall to determine

Table 5. Principal components (PC) and corresponding scoring coefficients for dietary variables derived from the food-frequency questionnaire in the study

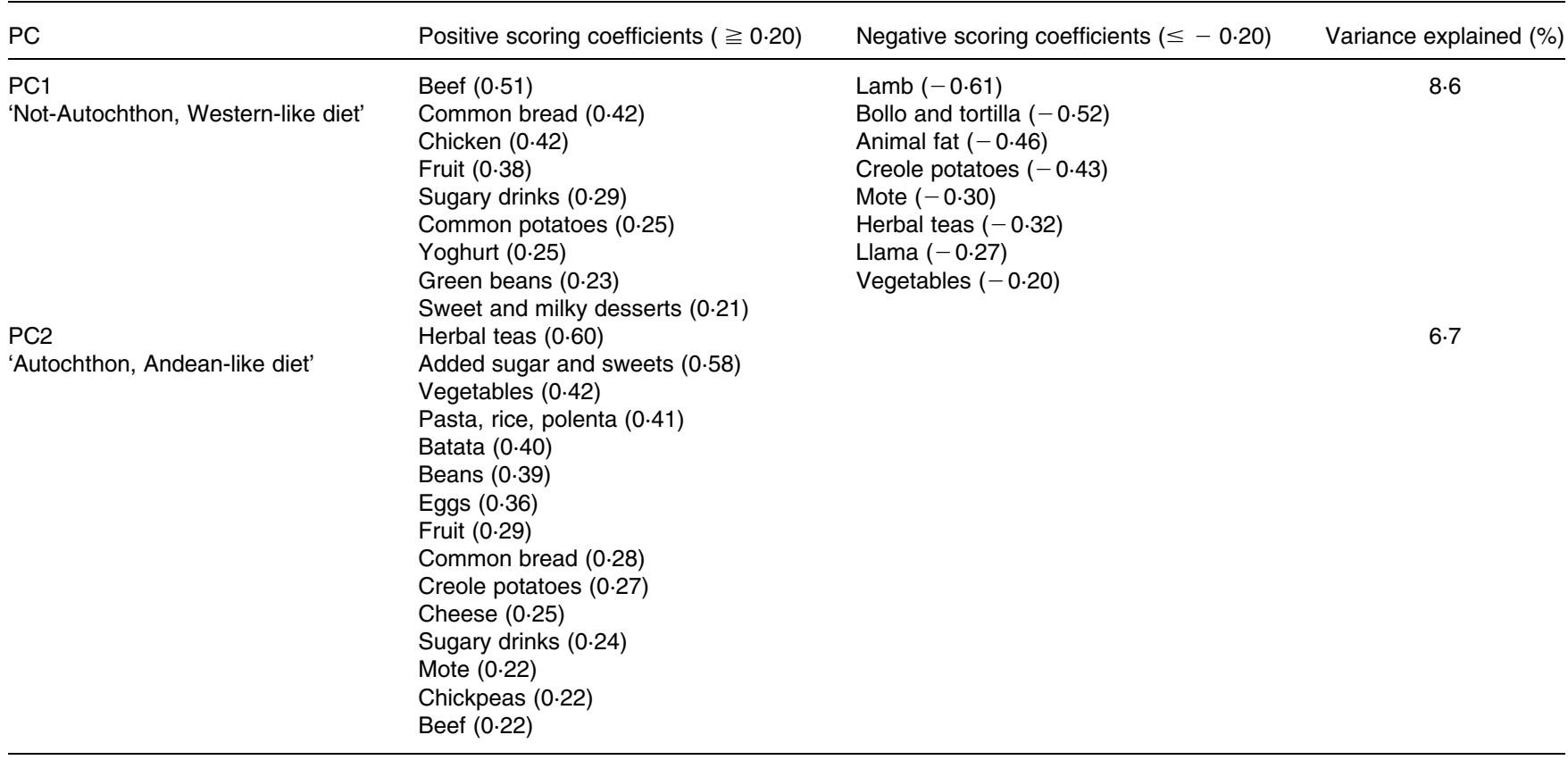


Table 6. Multiple, regression-derived coefficients $(\beta)$ and standard errors of specific predictors for the two principal components (PC1 and PC2)

\begin{tabular}{|c|c|c|c|c|c|c|}
\hline & \multicolumn{3}{|c|}{$\mathrm{PC} 1$} & \multicolumn{3}{|c|}{ PC2 } \\
\hline & $\beta$ & SE & $P$ & $\beta$ & SE & $P$ \\
\hline Age (per 10-year increment) & -0.05 & 0.02 & 0.003 & 0.01 & 0.02 & 0.711 \\
\hline \multicolumn{7}{|l|}{ Sex } \\
\hline Male & Baseline & & & Baseline & & \\
\hline Female & 0.01 & 0.06 & 0.868 & 0.07 & 0.07 & 0.350 \\
\hline \multicolumn{7}{|l|}{ Region } \\
\hline Quebrada & Baseline & & & Baseline & & \\
\hline Puna & -0.66 & 0.27 & 0.014 & 0.69 & 0.32 & 0.030 \\
\hline \multicolumn{7}{|l|}{ Area } \\
\hline Urban & Baseline & & & Baseline & & \\
\hline Rural & -0.49 & 0.04 & 0.000 & 0.09 & 0.04 & 0.030 \\
\hline \multicolumn{7}{|l|}{ Season } \\
\hline Post-harvest & Baseline & & & Baseline & & \\
\hline Pre-harvest & 0.36 & 0.27 & $0 \cdot 186$ & $-1 \cdot 24$ & 0.32 & 0.000 \\
\hline HSS (per 1-unit increment) & 0.13 & 0.02 & 0.000 & 0.07 & 0.03 & 0.003 \\
\hline
\end{tabular}

HSS, household status score.

food intake and the use of cross-border food composition tables to estimate nutrient intake. In the developing world high intra-individual variability in nutrient intake has been found, possibly caused by low food security, high day-today fluctuations in food supply and seasonal variation in food production ${ }^{5}$. In order to overcome possible day-to-day and seasonal variations in food intake, the questionnaires were administered homogeneously from Monday to Sunday and the fieldwork was carried out in two waves in order to collect data both in the post-harvest and pre-harvest season. Using cross-border food composition tables may be problematic, but unfortunately this is the case in this and other studies in developing countries ${ }^{4,5}$. In many situations, despite the introduction of random errors, the need to approximately assess the average intake of certain micronutrients in a community justifies the use of external food composition tables when no data are available in the studied country.

In conclusion, we have described median dietary intakes and food patterns of the Andean population of Puna and Quebrada of Humahuaca. Furthermore we have identified two dominant dietary patterns: one 'Western-like' pattern,

Table 7. Array of Spearman correlation coefficients between the two principal components (PC1 and PC2) and dietary variables

\begin{tabular}{lrrrrr}
\hline & \multicolumn{2}{c}{ PC1 } & & \multicolumn{2}{c}{ PC2 } \\
\cline { 2 - 3 } \cline { 5 - 6 } & $r$ & $P$ & & $r$ & $P$ \\
\hline Energy (kJ) & 0.01 & 0.867 & & -0.02 & 0.506 \\
Proteins (\% energy) & 0.17 & 0.000 & & -0.02 & 0.440 \\
Vegetable proteins (\% energy) & -0.03 & 0.341 & & 0.08 & 0.014 \\
Animal proteins (\% energy) & 0.14 & 0.000 & -0.06 & 0.037 \\
Carbohydrates (\% energy) & 0.00 & 0.936 & & 0.08 & 0.013 \\
Simple sugars (\% energy) & 0.13 & 0.000 & & 0.06 & 0.063 \\
Complex carbohydrates & -0.14 & 0.000 & & 0.02 & 0.564 \\
$\quad$ (\% energy) & & & & \\
Fibre (g/MJ) & -0.12 & 0.000 & & 0.07 & 0.032 \\
Lipids (\% energy) & -0.04 & 0.200 & & -0.08 & 0.012 \\
SFA (\% energy) & -0.23 & 0.475 & -0.06 & 0.071 \\
Cholesterol (mg/MJ) & 0.15 & 0.000 & -0.01 & 0.845 \\
\hline
\end{tabular}

reflecting the consequences of the nutrition transition in this population and one 'Andean-like' pattern present in some rural but developed areas of the region. The 'Western-like' dietary pattern tends to be associated with a worse diet quality (in terms of the macronutrient content of the diet) in relation to the 'Andean-like' pattern. The nutrition transition in this community might be one of the leading causes of the observed double burden of malnutrition.

\section{Acknowledgements}

The present study was supported by grants from the Spanish Agency for International Cooperation (AECI) and from the Cooperation and Immigration Ministry of the Balearic Islands Government. The authors are grateful to the Agents of Health Primary Attention, Ministry of Social Welfare, Province of Jujuy (Argentina). We give special thanks to N. Farfán, M. Lobo, C. Pérez Martínez, J. Gutiérrez, M. A. Jiménez, M. D. Juárez, S. Burke, M. E. Acuña, S. Chañi and E. Jiménez.

\section{References}

1. Leonard WR \& Thomas RB (1989) Biosocial responses to seasonal food stress in highland Peru. Hum Biol 61, 65-85.

2. Valda M \& Cajias M (1992) De Como se Alimentaban Nuestros Antepasados Antes de la Llegada de los Españoles: Memoria Historica MH-7 (How our Ancestors Fed Themselves before the Arrival of the Spaniards). La Paz: Hilbol.

3. Graham MA (2004) 'No somos iguales': the effect of household economic standing on women's energy intake in the Andes. Soc Sci Med 58, 2291-2300.

4. Berti P, Leonard W \& Berti W (1998) Stunting in an Andean community: prevalence and etiology. Am J Hum Biol 10, 229-240.

5. Berti PR \& Leonard WR (1998) Demographic and socioeconomic determinants of variation in food and nutrient intake in an Andean community. Am J Phys Anthropol 105, 407-417.

6. Leonard WR, Dewalt KM, Stansbury JP \& McCaston MK (2000) Influence of dietary quality on the growth of highland and coastal Ecuadorian children. Am J Human Biol 12, $825-837$. 
7. Macdonald B, Johns T, Gray-Donald K \& Receveur O (2004) Ecuadorian Andean women's nutrition varies with age and socioeconomic status. Food Nutr Bull 25, 239-247.

8. Graham MA (1997) Food allocation in rural Peruvian households: concepts and behavior regarding children. Soc Sci Med 11, 1697-1709.

9. Quiroz R, León-Velarde C, Valdivia R, Zorogastúa FP, Baigorria G, Barreda C, Reinoso J, Holle M \& Li Pun H (2003) Case six. Project title - Making a difference to Andean livelihoods through an integrated research approach. In Research Towards Integrated Natural Resources Management - Examples of Research Problems, Approaches and Partnerships in Action in the CGIAR, ch. 3, pp. 113-124 [RR Harwood and AH Kassam, editors]. Rome: FAO.

10. Moreno Romero S, Jail Colome J, Lomaglio D, Marrodán MDM, Dipierri JE, Alba J \& Lejtman NL (2005) Condición nutricional en la Puna Argentina (Nutritional conditions in Puna, Argentina). Observatorio Medioambiental 8, 111-125.

11. Bermudez OI \& Tucker KL (2003) Trends in dietary patterns of Latin American populations. Cad Saude Publica 19, Suppl. 1, S87-S99.

12. Popkin BM (2004) The nutrition transition: an overview of world patterns of change. Nutr Rev 62, S140-S143.

13. Popkin BM, Richards MK \& Montiero CA (1996) Stunting is associated with overweight in children of four nations that are undergoing the nutrition transition. J Nutr 126, 3009-3016.

14. Salomon F \& Schwartz S (1999) The Cambridge History of the Native Peoples of the Americas. two-part set. Cambridge, UK: Cambridge University Press.

15. Food and Agriculture Organization \& LATINFOODS (2002) Tabla de Composición de Alimentos de América Latina. http://www.rlc.fao.org/bases/alimento

16. Moreiras O, Carvajal A, Cabrera L \& Cuadrado C (2003) Tablas de Composición de Alimentos, 7th ed. Madrid: Pirámide.

17. Mataix J \& Mañas M (1998) Tablas de Composición de Alimentos Españoles, 3rd ed. Granada: INTA-Universidad de Granada.

18. Frisancho A (1990) Anthropometric Standards for the Assessment of Growth and Nutritional Status. Ann Arbor, MI: University of Michigan Press.

19. World Health Organization (1995) Physical Status: the Use and Interpretation of Anthropometry. Report of a WHO Expert Committee. WHO Technical Report Series no. 854. Geneva: WHO.
20. Bailey K \& Ferro-Luzzi A (1995) Use of body mass index of adults in assessing individual and community nutritional status. Bull World Health Organ 73, 673-680.

21. Willet W (1998) Nutritional Epidemiology, 2nd ed. New York: Oxford University Press.

22. Chatfield C \& Collins A (1995) Introduction to Multivariate Analysis. London: Chapman \& Hall.

23. Romaguera D, Lobo M, Farfán N, Pons A, Sammán N \& Tur J (2007) Nutritional status of the Andean population of Puna and Quebrada of Humahuaca, Jujuy, Argentina. Public Health Nutr (In the Press).

24. Caballero B (2005) A nutrition paradox - underweight and obesity in developing countries. N Engl J Med 352, 1514-1516.

25. Doak CM, Adair LS, Bentley M, Monteiro C \& Popkin BM (2005) The dual burden household and the nutrition transition paradox. Int J Obes (Lond) 29, 129-136.

26. Garrett JL \& Ruel MT (2005) Stunted child-overweight mother pairs: prevalence and association with economic development and urbanization. Food Nutr Bull 26, 209-221.

27. Filozof C, Gonzalez C, Sereday M, Mazza C \& Braguinsky J (2001) Obesity prevalence and trends in Latin-American countries. Obes Rev 2, 99-106.

28. Caballero B (2001) Introduction. Symposium: obesity in developing countries: biological and ecological factors. J Nutr 131, $866 \mathrm{~S}-870 \mathrm{~S}$

29. Uauy R, Albala C \& Kain J (2001) Obesity trends in Latin America: transiting from under- to overweight. J Nutr 131, 893S-899S

30. Florencio TM, Ferreira HS, de Franca AP, Cavalcante JC \& Sawaya AL (2001) Obesity and undernutrition in a very-lowincome population in the city of Maceio, northeastern Brazil. Br J Nutr 86, 277-284.

31. Hoffman D, Sawaya A, Verreschi I, Tucker K \& Roberts S (2000) Why are nutritionally stunted children at increased risk of obesity? Studies of metabolic rate and fat oxidation in shantytown children from Sao Paulo, Brazil. Am J Clin Nutr $\mathbf{7 2}$ 702-707.

32. Schroeder DG, Martorell R \& Flores R (1999) Infant and child growth and fatness and fat distribution in Guatemalan adults. Am J Epidemiol 149, 177-185.

33. Graham MA (2003) Seasonal dietary stress in Peruvian children. J Trop Pediatr 49, 24-27. 